\title{
Nash bargaining solutions for international climate agreements under different sets of bargaining weights
}

\author{
S. Yu ${ }^{1} \cdot$ E. C. van Ierland ${ }^{1} \cdot$ H.-P. Weikard ${ }^{1}$ • \\ X. Zhu' ${ }^{1}$
}

Accepted: 1 February 2017/Published online: 8 February 2017

(C) The Author(s) 2017. This article is published with open access at Springerlink.com

\begin{abstract}
Bargaining is a tool to share collaborative gains and to facilitate reaching agreement. To improve incentives to join an international climate agreement (ICA), the Nash bargaining solution can be used to distribute cooperative gains across signatories. In this paper, we examine how the formation of ICAs and their mitigation efficiency are impacted by the use of the Nash bargaining solution. In a Nash bargaining game with heterogeneous players, bargaining powers are unequal and may be driven by different characteristics of the players. We employ different sets of asymmetric bargaining weights in order to examine the effectiveness of climate coalitions that emerge as stable agreements. Using the Nash bargaining solution, we obtain results from the stability of coalition model (STACO). We find that the Nash bargaining solution can improve the participation incentives and performances of ICAs as compared to agreements that do not redistribute gains from cooperation, but its capacity to overcome free-riding incentives is limited. However, if Nash bargaining accounts for outside options of players, we find larger stable coalitions and higher global abatement levels. In fact, Nash bargaining with outside options can stabilise the largest coalitions that can possibly be stable in our game.
\end{abstract}

Keywords International environmental agreements - Bargaining power - Climate agreements · Optimal transfers · STACO model

\section{Introduction}

Mitigation of greenhouse gas (GHG) emissions is costly. Due to the public good property of GHG emissions mitigation, each individual country has an incentive to free ride on the abatement efforts of other countries. However, through multilateral negotiations an international climate agreement can be formed to alleviate the social dilemma (Carraro and

S. Yu

shumin.yu@wur.nl

1 Environmental Economics and Natural Resources Group, Wageningen University, P.O. Box 8130, 6700 EW Wageningen, The Netherlands 
Siniscalco 1993; Finus 2003). A climate agreement comprises a mitigation target for members, but also needs to distribute gains from cooperation.

The distribution of coalitional gains across countries can be organised through transfer schemes which are effective instruments to offset free-riding incentives and improve the stability of international climate agreements (ICAs) (Carraro and Siniscalco 1993; Barrett 1995; Botteon and Carraro 1997; Rose et al. 1998; Rose and Stevens 1998; Weikard et al. 2006; Carraro et al. 2006; Weikard 2009; Nagashima et al. 2009). Sharing the gains of cooperation is solving a bargaining problem (Nash 1950; Powell 2002); hence, the Nash bargaining solution (NBS) can be used to determine transfer schemes for ICAs. Carraro and Siniscalco (1993) analyse the role of welfare transfers for coalition stability among symmetric players when transfers are determined by applying the Nash bargaining solution. Their theoretical results show that the size of stable coalitions can be extended by 'bribing' singletons with transfers. Botteon and Carraro (1997) and Carraro et al. (2006) apply the Nash bargaining rule to surplus sharing within coalitions. They extend the analysis to asymmetric players, and their results are derived resorting to numerical analysis. However, previous studies on the application of a Nash bargaining rule assume equal bargaining weights among countries and do not take the different bargaining powers of asymmetric countries into account. Bargaining powers determine the sharing of collective gains which, in turn, determines the incentives to join a climate agreement. In this paper, we assume that the distribution of gains is the outcome of a bargaining process with unequal bargaining power, and thus, transfers are determined by bargaining power. We employ the Nash bargaining solution to model the distribution of cooperative gains. The bargaining outcome is subject to bargaining power. The key issue is what constitutes the bargaining power of each negotiator. Costantini et al. (2015) provide a sketch of future potential bargaining positions of developing countries in climate negotiations according to key structural features like economic power, geographic, environmental and social characteristics, and the energy system. Considering the importance of bargaining power in climate negotiations, we discuss and review potential reasons that could induce differences of negotiators' bargaining power in international climate negotiations. Thus, determinants of bargaining power can be identified and then used for the quantification of negotiators' bargaining weights. Furthermore, we model the international climate negotiations as a Nash bargaining game in which cooperative gains are distributed based on the NBS with asymmetric bargaining power, and we study which climate coalitions could form, given the different bargaining powers of the negotiators.

Although Nash bargaining has been used as a transfer scheme in the literature on ICAs, it has not been investigated in depth for the surplus sharing of coalitional gains among countries with unequal bargaining powers. The novelty of this paper is that we explore the impact of using the NBS for distributing coalitional gains under different sets of bargaining weights on the stability and effectiveness of international climate agreements. We consider different possible determinants of bargaining power which are exogenously determined in our model. Our analysis complements the set of coalitional surplus sharing rules.

In this paper, we identify five different factors that can determine negotiators' bargaining power. (1) In bargaining theory, time preference, i.e. the willingness to wait for the payoff is often proposed as a driving factor that can influence the distribution of gains. A player who is more patient has more bargaining power (Rubinstein 1982; Binmore et al. 1992; Powell 2002). Thus, we use time preference represented by the discount factor to determine bargaining power of negotiating countries. (2) In climate negotiations, it is commonly argued that the distribution of cooperative payoffs should be in accordance with abatement efforts. Larger efforts give a claim to a larger share of the gains. Hence, we use 
the proportion of individual abatement in a coalition to represent each negotiator's bargaining weight. (3) Another way to assess efforts is to use abatement costs. This is different from (2) if countries differ in marginal costs of abatement. Larger costs could justify a larger claim. Thus, we use countries' total abatement costs, reflecting their monetary efforts as an indicator of bargaining power. (4) Abatement benefits of a country reflect the avoided damages from reducing GHG emissions which are associated with a country's vulnerability to climate change. A country that is more vulnerable to climate change will be more eager to get involved in the climate cooperation than a country that is less vulnerable. Hence, we use the inverse of abatement benefits as an indicator of bargaining power. (5) In international negotiations, economically powerful countries can be more successful in shaping the agreement. We therefore take the economic power measured by gross domestic product (GDP) as an indicator of bargaining power.

To compare and examine the impact of the NBS with different sets of unequal bargaining weights on incentives to cooperate, we formulate a two-stage cartel formation game. At the first stage, each country decides whether to participate in a climate coalition or not by evaluating payoffs received from being a signatory or a singleton. At the second stage, abatement targets are set cooperatively by coalition members, but their individual payoffs are determined by applying the NBS with a given set of bargaining weights.

A bargaining solution is not just affected by bargaining power, but also by players' outside options (Wagner 1988; Powell 2002). A decision to take up an outside option implies a withdrawal from the bargaining process. The outside option payoff imposes a lower bound on the bargaining solution since no one must accept an agreement that makes him worse off compared to what he can obtain otherwise (Binmore et al. 1992; Muthoo 1999). For the bargaining problem of international climate agreements, we assume that a country's outside option is to abstain from an agreement and to remain a singleton player. This is in line with Muthoo (1999, p. 105) who explains that outside options do not affect the disagreement point. The Nash bargaining solution with outside options falls in the class of optimal sharing rules described by Carraro et al. (2006) and Weikard (2009). Hence, our paper provides an additional motivation for the use of optimal sharing rules.

We adopt the concept of internal and external stability to analyse our game (cf. D'Aspremont et al. 1983). An agreement is internally stable if no member wants to leave. It is externally stable if no other player wants to join. This implies that we consider only single deviations which define the outside option payoffs. If a deviation would trigger others' withdrawal from the coalition, a simple internal/external stability concept would not be adequate and more sophisticated solution concepts such as coalition proof equilibrium (Bernheim et al. 1987) or farsighted stability (Chwe 1994) could be employed. De Zeeuw (2008) shows that farsighted coalition stability can lead to larger stable coalitions with higher global welfare. Another assumption that we adopt is that we allow only for one coalition. A deviator from the coalition becomes a singleton and cannot make an agreement with other players. Allowing for multiple coalitions would lead to higher abatement levels and global welfare as has been shown by Asheim et al. (2006) and Sáiz et al. (2006). However, in this paper we do not consider the possibility of multiple coalition structures and we confine the analysis to internal and external stability. The implications of refined solution concepts are left to future research.

To see how different sets of bargaining weights and the relevance of outside options impact coalition stability, we compare results from the STACO (stability of coalitions) model. STACO is a global model with calibrated abatement costs and benefits functions for 12 world regions. We use it to test stability of the $2^{12}-12$ possible coalitions that may 
form. Our results provide implications of sharing rules based on the NBS and also its impact on the formation and stability of ICAs.

In what follows, we present the game in Sect. 2. Section 3 discusses potential determinants of bargaining power, i.e. we introduce different sets of bargaining weights used in the NBS for distributing cooperative gains. Section 4 describes the STACO model and our numerical results in more detail. The paper ends with discussions and conclusions in Sect. 5 .

\section{The game theoretical model}

We consider a set of players $N=\{1,2, \ldots, n\}$ representing countries or regions that negotiate an agreement on mitigating GHG emissions. We allow for asymmetric abatement benefits and costs. The formation of a climate agreement is modelled by the following a two-stage game.

Stage 1 All players $(i \in N)$ announce whether to sign an agreement or not. Their decisions are made non-cooperatively and simultaneously. Formally, an agreement is a subset of the set of players. The set of all possible agreements is:

$$
\zeta=\{S \subseteq N \mid s \geq 2\}, \quad|\zeta|=2^{n}-(n+1) .
$$

where $s=|S|$ represents the number of signatories. If negotiations fail, then there is no agreement and all players remain singletons.

Stage 2 At the second stage signatories $S$ and the remaining singletons play a transboundary pollution game. Abatement strategies are chosen simultaneously by signatories and singletons. Signatories $(i \in S)$ decide on their abatement by maximising their aggregated payoffs; non-signatories $(i \in N \backslash S$ ) maximise their individual payoff. If no agreement has been reached at stage 1, payoffs are determined by the non-cooperative equilibrium outcome of a $n$-player transboundary pollution game. We denote this outcome by $D$ as it represents the disagreement point of the bargaining game.

The set of abatement choices by all players can be defined as $\boldsymbol{q}=\left(q_{1}, \ldots, q_{n}\right)$ with the condition $q_{i} \in\left[0, \bar{e}_{i}\right]$, where $\bar{e}_{i}$ denotes the business-as-usual emissions level. Once abatement is chosen, the individual signatory's payoff denoted by $\pi_{i}(\boldsymbol{q})$ can be determined, where $\boldsymbol{q}$ denotes the abatement vector. The coalitional gains of the agreement $S$ are the difference between the aggregate payoff of signatories $\sum_{i \in S} \pi_{i}(\boldsymbol{q})$ and what they would get in case of disagreement. The final payoffs of signatories denoted by $\pi_{i}^{*}$ are based on the NBS used to redistribute the coalitional gains. The set of weights reflecting bargaining power is denoted by $\left\{\lambda_{i}\right\}_{i \in S}$. It is exogenously determined in our model.

Note that in our game, we only consider the formation of one single agreement, such that a player deviating from $S$ becomes a non-signatory. Therefore, the outside option for each signatory $i \in S$ in our Nash bargaining game is the payoff received as a singleton when other players maintain their membership status. In this setting, for an agreement $S$ with only two signatories (i.e. $s=2$ ), the outside option is identical to the disagreement point or status quo, but in general this is not the case. Obviously, an agreement $S$ can be accepted by a signatory if and only if its coalitional payoff is larger than its outside option payoff.

We solve this two-stage game by backward induction in order to identify the sub-game perfect Nash equilibria. At stage 2, the signatories $i \in S$ choose their optimal abatement 
levels $q_{i}$ by maximising joint payoffs denoted by $\sum_{i \in S} \pi_{i}$. We have the following maximisation problem for signatories $i \in S$ :

$$
\max _{q_{i}} \sum_{i \in S} \pi_{i}(\boldsymbol{q})=\sum_{i \in S}\left(B_{i}(q)-C_{i}\left(q_{i}\right)\right) .
$$

where $q=\sum_{i \in N} q_{i}$ denotes the global abatement level. The abatement cost function denoted by $C_{i}\left(q_{i}\right)$ is increasing and strictly convex, i.e. $C_{i}^{\prime}\left(q_{i}\right)>0$ and $C_{i}^{\prime \prime}\left(q_{i}\right)>0$. Abatement benefits $B_{i}(q)$, depend on the overall level of abatement $q$ and are assumed to be linearly increasing, i.e. $B_{i}^{\prime}(q)>0$ and $B_{i}^{\prime \prime}(q)=0$, implying a dominant strategy for each player. The equilibrium condition for signatories $i \in S$ is derived from the first-order condition of problem (1):

$$
C_{i}^{\prime}\left(q_{i}^{*}\right)=\sum_{j \in S} B_{j}^{\prime}\left(q^{*}\right)
$$

At this stage, each non-signatory maximises its own payoffs. The problem for nonsignatories can be formulated as follows:

$$
\max _{q_{i}} \pi_{i}(\boldsymbol{q})=B_{i}(q)-C_{i}\left(q_{i}\right) .
$$

The equilibrium condition for singletons $i \in N \backslash S$ can be obtained by deriving the firstorder condition of the problem (3). This gives $B_{i}^{\prime}\left(q^{*}\right)=C_{i}^{\prime}\left(q_{i}^{*}\right)$.

Based on abatement choices of all players, the payoffs of signatories and singletons can be determined. Signatories redistribute the aggregated payoffs $\sum_{i \in S} \pi_{i}(\boldsymbol{q})$ based on the NBS. Their bargaining powers are unequal and given by a set of bargaining weights $\left\{\lambda_{i}\right\}_{i \in S}$. The redistributed payoff under the NBS can be represented by a set denoted by $\left\{\pi_{i}^{*}\right\}_{i \in S}$, which solves the Nash bargaining problem described as follows:

$$
\max _{\left\{\pi_{i}^{*}\right\}_{i \in S}} \prod_{i \in S}\left(\pi_{i}^{*}-\bar{\pi}_{i}\right)^{\lambda_{i}}, \text { s.t. } \pi_{i}^{*} \geq \bar{\pi}_{i}, \pi_{1}^{*}+\ldots+\pi_{s}^{*}=\sum_{i \in S} \pi_{i}(\boldsymbol{q})
$$

in which $\bar{\pi}_{i}$ represents the non-cooperative payoffs of signatories $i \in S$, which is the disagreement point $\left(\left(\bar{\pi}_{i}\right)_{i \in S}=D\right)$. We assume that gains from cooperation can be redistributed among signatories without incurring transactions costs. Therefore, the bargaining set is convex and compact which ensures the uniqueness of the solution of bargaining problem (4). Signatories' bargaining weights satisfy the condition $\sum_{i \in S} \lambda_{i}=1$. A higher value of $\lambda_{i}$ indicates a strategic advantage in the bargaining process.

At stage 1, all players decide to sign an agreement or not. Here, we use the partition function $V_{i}(S)$ that can be derived from the solution of the stage 2 game to represent each player's payoffs under the coalition $S$ based on the NBS. Note that a signatory receives its outside option payoffs when deviating from the coalition $S$, denoted by $V_{i}(S \backslash\{i\})$. The Nash equilibrium of the stage 1 game satisfies the following internal and external stability conditions (d'Aspremont et al. 1983).

Internal stability:

$$
V_{i}(S) \geq V_{i}(S \backslash\{i\}), i \in S
$$

External stability:

$$
V_{i}(S) \geq V_{i}(S \cup\{i\}), i \in N \backslash S .
$$




\section{The representation and interpretation of different sets of bargaining weights}

In this section, we discuss factors that could lead to differences in countries' bargaining power in international climate negotiations. Based on these factors, weights of bargaining power can be identified that will be used to determine the bargaining outcomes and, hence, the individual payoffs for all coalition members. We also explain the relevance of outside options in our game and discuss their role for stable climate agreements.

\subsection{Bargaining weights based on discount factor}

Gains from cooperation can only be obtained when an agreement is reached. A delay of reaching an agreement is costly (Rubinstein 1982; Muthoo 1999). This is particularly relevant for climate agreements: the sooner cooperation is achieved, the smaller the climate damages will be (Courtois and Tazdaiit 2014). Binmore et al. (1986) show that in a bargaining game players' time preferences impact their strategic choices and thus the bargaining solution. The discount factor reflects a player's willingness to wait and can be used as an indicator of the negotiators' bargaining power.

Over time, the net present value (NPV) of the gains from cooperation falls quicker for a region with a higher discount rate than for a region with a lower discount rate. Therefore, the higher a region's discount rate, the stronger its preference for an ICA that is formed and implemented earlier. Regions with a strong preference to reach an agreement are more willing to give in. They will have a larger cost of waiting and therefore less bargaining power.

Let $r_{i}$ be the discount rate prevailing in region $i$. We use the discount factor denoted by $\delta_{i} \equiv \frac{1}{1+r_{i}}$ to represent the bargaining power of signatory $i$ in the negotiation. The corresponding bargaining weight can be represented as:

$$
\lambda_{i}=\frac{\delta_{i}}{\sum_{j \in S} \delta_{j}}, i \in S .
$$

Under this set of bargaining weights, regions with relative lower discount rates are expected to have stronger participation incentives induced by higher bargaining weights and a larger share of coalitional gains.

\subsection{Bargaining weights based on abatement efforts}

As compared to developed regions with high marginal abatement costs and benefits, developing regions with low marginal abatement costs and benefits have less incentives to join a climate coalition. The main reason is that developing regions contribute larger shares of global abatement but with lower private returns. Considering the importance of developing regions' contribution to abatement, it can be argued that regions engaging in greater abatement efforts, if they join, can ask for a larger share of the gains. Hence, we use the proportion of individual abatement in a coalition to represent each negotiator's bargaining weight. The larger the mitigation efforts of a coalition member, the larger its bargaining power in the negotiation over coalitional gains. The bargaining weight based on abatement efforts can be formulated as: 


$$
\lambda_{i}=\frac{q_{i}^{*}}{\sum_{j \in S} q_{j}^{*}}, i \in S
$$

in which $q_{i}^{*}$ is the equilibrium abatement level of each signatory $i$ of coalition $S$. It can be expected that under this set of bargaining weights, regions contributing larger shares to the coalitional abatement will have more incentives to participate.

\subsection{Bargaining weights based on abatement costs}

Within a climate coalition, due to differences in the technological development and the resulting differences in marginal abatement costs between countries, a large abatement assignment of a member does not necessarily imply high total abatement costs if marginal abatement costs are low. Hence, abatement effort $q_{i}$ does not accurately reflect the cost each member pays for cooperation. The controversy about collaborative gains allocation that is induced by countries' uneven costs for mitigation cooperation has been a recurring issue put on the negotiation table (Barrett and Stavins 2003; Carraro et al. 2006). Generally, countries taking on larger abatement costs would claim compensation in the form of a larger share of the cooperative gains. If the total abatement is seen as a joint effort requiring investment, then the gains from cooperation should be distributed proportional to these investments. Hence, a country's abatement cost can be identified as a source of asymmetry in bargaining power during negotiations on climate cooperation. We take the abatement cost of a country as a measure of its bargaining power. The bargaining weight can be formulated as follows:

$$
\lambda_{i}=\frac{C_{i}\left(q_{i}^{*}\right)}{\sum_{j \in S} C_{j}\left(q_{j}^{*}\right)}, i \in S .
$$

Under such a set of bargaining weights, the higher a country's abatement cost, the higher will be its share of the gains from cooperation.

\subsection{Bargaining weights based on climate change damages}

Damages resulting from climate change differ across regions due to different impacts of climate change, different economic losses and different valuations of environmental quality. Regions facing high damages are eager to mitigate climate change. However, the low-damage regions have less incentives to join the cooperation. This difference in preferences for climate cooperation implies that low-damage countries hold more bargaining power than high-damage countries.

In our model, abatement benefits are avoided climate change damages. Hence, we use abatement benefits to represent climate change vulnerability. Bargaining power is then inversely related to climate change vulnerability. The bargaining weight based on damages can be represented as

$$
\lambda_{i}=\frac{\frac{1}{B_{i}\left(q^{*}\right)}}{\sum_{j \in S} \frac{1}{B_{j}\left(q^{*}\right)}}, i \in S .
$$

From Eq. (10), it is straightforward to see that higher benefits from global abatement are associated with lower bargaining power and a lower bargaining weight $\lambda_{i}$. 


\subsection{Bargaining weights based on economic power}

In international negotiations among asymmetric regions, the economic power reflected by the GDP of a region can affect its bargaining power. Generally, regions which are characterised by a larger GDP can exert more influence over the regions with a lower GDP, for example, through issue linkage. Issue linkage connects environmental negotiations with other economic issues (e.g. trade or technological cooperation). Issue linkage can offset free-riding incentives in climate cooperation (Carraro and Siniscalco 1993, 1995). In climate negotiations, regions with an economic advantage can put pressure on poorer regions with 'sticks and carrots'. For example, they can withhold or offer technological cooperation. Therefore, regions who have advantage in economic power have larger bargaining power in climate negotiations. Based on this argument, economically powerful regions can obtain a larger share of the joint payoff. This reasoning has also been put forward by Rose et al. (1998) where they discuss a transfer rule based on income claims. Determining negotiators' bargaining power by economic power, the bargaining weight can be represented as:

$$
\lambda_{i}=\frac{G D P_{i}}{\sum_{j \in S} G D P_{j}}, i \in S
$$

\subsection{Outside options}

In the bargaining game, outside options introduce a lower bound on each player's payoff. The presence of outside options can thus affect the negotiation outcome by considering the impact of the minimum payoff a player can assure for himself when leaving the negotiation. Hence, in our game we assume that a region's outside option is to abstain from an agreement and to remain a singleton player. As mentioned before, a player's outside option payoff can be written as $V_{i}(S \backslash\{i\})$. In the literature of examining coalition stability in cartel games, it has been pointed out that coalition $S$ can be internally stable whenever the coalition payoff does not fall short of the sum of members' outside options, i.e.

$$
\sum_{i \in S} V_{i}(S) \geq \sum_{i \in S} V_{i}(S \backslash\{i\}) .
$$

Inequality (12) is a necessary condition for internal stability of coalition $S$. If we consider a bargaining solution with outside options, then the outside option payoff is guaranteed for each signatory whenever (12) is satisfied. Carraro et al. (2006) and Weikard (2009) have called solutions satisfying internal stability when (12) holds 'optimal transfers', since payoffs are re-arranged to incentivise participation in the agreement. It is obvious then that bargaining with outside options belongs to the class of optimal transfer rules. It is important to note that the set of stable coalitions is not affected by the distribution of the surplus that remains after all signatories have received their outside option payoffs. This implies that in our game, under bargaining with outside options, the set of stable coalitions is independent of bargaining weights $\lambda_{i}$. Hence, for the analysis of stability there is no need to apply different sets of bargaining weights. 


\section{Simulations and results}

In this section, we describe the implementation of the simulation analysis employing the STACO model in Sect. 4.1. Section 4.2 presents the simulation results and a discussion of our findings concerning stability and effectiveness of coalitions under the NBS. We examine the relevance of outside options in Sect. 4.3. All results and discussions in this section are based on the STACO 3 model as documented by Nagashima et al. (2011) and Dellink et al. (2015).

\subsection{Simulations employing the STACO model}

To gain practical insights into the implications of the NBS with different sets of bargaining weights, we employ a numerical simulation model, the STACO model. The STACO model is a combined game-theoretic and integrated assessment model created to examine the formation and performances of international climate agreements among twelve world regions as specified in Table 5 in Appendix (cf. also Nagashima et al. 2011; Dellink et al. 2015). By specifying the abatement benefit and cost functions for these twelve heterogeneous regions, the STACO model enables us to analyse coalition stability, abatement levels, efficiency and welfare. Considering inertia of the climate system, the simulation analysis in STACO adopts a 100-year time horizon (from 2010 to 2110). The formation of an ICA in STACO is a standard two-stage cartel formation game, in which the membership decision is taken once and for all periods. The abatement choice of each player $i$ for the whole time horizon can be represented by an abatement path $\left(q_{i, 1}^{*}, \ldots, q_{i, 100}^{*}\right)$. Accordingly, the payoffs of each player over the planning horizon can be represented as a payoff path $\left(\pi_{i, 1}^{*}, \ldots, \pi_{i, 100}^{*}\right)$. Finally, the stability of a climate coalition is checked based on the net present value of the payoff stream over 100 years according to the internal and external stability conditions (5) and (6). For a full specification of the latest version of the STACO model (STACO 3), the reader is referred to Nagashima et al. (2011) and Dellink et al. (2015).

For our simulations, we use the numerical computing software MATLAB. For each period, signatories and singletons decide their optimal abatement $q_{i, t}^{*}$ according to Eqs. (2) and (3). Accordingly, the payoffs of signatories can be derived in each period based on Nash bargaining solutions described in Eq. (4). The payoffs of singletons are the net gains from abatement. In particular, each signatory's bargaining weight $\lambda_{i, t}$ in each period is based on the value of different determining factors at each period, for example, the discount factor $\delta_{i, t}$, abatement $q_{i, t}^{*}$, abatement costs $C_{i, t}\left(q_{i, t}^{*}\right)$, climate change damages $\frac{1}{B_{i, t}\left(q_{t}^{*}\right)}$ and economic power $G D P_{i, t}$. For each set of bargaining weights, we calculate the abatement and payoffs path of each region under every coalition that can be formed. Finally, based on the calculation of the NPV of each player's payoff stream over 100 years we perform a stability check for each coalition according to Eqs. (5) and (6).

\subsection{Results for the Nash bargaining solution without consideration of outside options}

In this section, we report and discuss results on coalition formation and performances under the NBS with different sets of bargaining weights. The role of outside options is discussed in Sect. 4.3. 
To compare our surplus sharing scheme based on the NBS with other conventional sharing schemes that are frequently discussed (for example, egalitarian, historical responsibility or ability to pay), we calculate transfers generated in NBS under the five different sets of bargaining weights for the grand coalition. Table 1 illustrates the amount of transfers for each region under various sets of bargaining weights. Regions with negative transfers are payers, and regions with positive transfers are receivers. Due to high marginal abatement benefits, USA, JPN and EUR can benefit more than other regions. Hence, USA, JPN and EUR are always transfer payers under all five sets of bargaining weights. This result is in line with the result under the egalitarian and ability-to-pay sharing scheme calculated by Altamirano-Cabrera and Finus (2006) using STACO. However, JPN becomes a transfer receiver under a historical responsibility rule. This is due to the low business-as-usual emissions of JPN, implying that JPN contributes less to the current GHG concentration, and thus, JPN has a low mitigation target. In terms of the amount of transfers, JPN and EUR are the two largest payers and their payments are much larger than under the egalitarian and ability-to-pay rule in Altamirano-Cabrera and Finus (2006). In contrast, USA pays the largest amount of transfers under the egalitarian and ability-to-pay rule in Altamirano-Cabrera and Finus (2006). This is due to USA's relatively large population and high GDP per capita. From Table 1, it can also be seen that CHN and BRA always receive the largest amounts of transfers under different bargaining weights. This also explains why CHN and BRA have strong participation incentives as shown in Table 2. When other conventional sharing rules are applied, IND and BRA are the largest transfer receivers (Altamirano-Cabrera and Finus 2006).

Now we turn to the stability results when the NBS is used to redistribute coalitional gains. Firstly, our results show that all coalitions with two members are internally stable. As explained by Weikard et al. (2006), this result is related to the linear functional form of abatement benefits and non-negative weights, which ensure a positive coalitional surplus. Thus, being a signatory of a two-member coalition gives a larger payoff than that of being

Table 1 Transfers determined by a NBS under different sets of bargaining weights: grand coalition

\begin{tabular}{lrrrrr}
\hline Regions & $\begin{array}{l}\text { Discount } \\
\text { factor }\end{array}$ & $\begin{array}{l}\text { Abatement } \\
\text { efforts }\end{array}$ & $\begin{array}{l}\text { Climate change } \\
\text { damages }\end{array}$ & $\begin{array}{l}\text { Abatement } \\
\text { costs }\end{array}$ & $\begin{array}{l}\text { Economic } \\
\text { power }\end{array}$ \\
\hline USA & -6364.37 & -5687.02 & -6209.24 & -3275.24 & -1312.63 \\
JPN & -7784.00 & $-12,176.82$ & $-11,725.37$ & $-12,608.12$ & -8925.65 \\
EUR & $-12,470.40$ & $-13,604.72$ & $-12,568.08$ & $-12,251.56$ & -8135.26 \\
OHI & 2609.60 & -214.57 & 3603.85 & 1862.57 & 1625.68 \\
ROE & 1289.63 & 492.82 & 2565.22 & 262.06 & 1194.35 \\
RUS & 3735.38 & 1109.04 & 5010.89 & 2116.59 & 862.58 \\
HIA & 2535.77 & 1278.78 & 4356.11 & 3903.70 & 1859.10 \\
CHN & 2471.66 & 4876.11 & 3010.30 & 4991.20 & 4383.22 \\
IND & 1164.29 & 1234.09 & 1584.42 & 1422.41 & 583.73 \\
MES & 2162.61 & 2431.62 & 5254.77 & 2684.92 & 1173.04 \\
BRA & 4842.53 & 810.31 & 7591.57 & 822.07 & 1732.48 \\
ROW & 1506.56 & 2181.38 & 2247.70 & 3810.50 & 3079.45 \\
Total & 0 & 0 & 0 & 0 & 0 \\
\hline All & 0 & 0 & 0 & 0
\end{tabular}

All figures are expressed as NPV of transfers (bln\$) over 100 years 


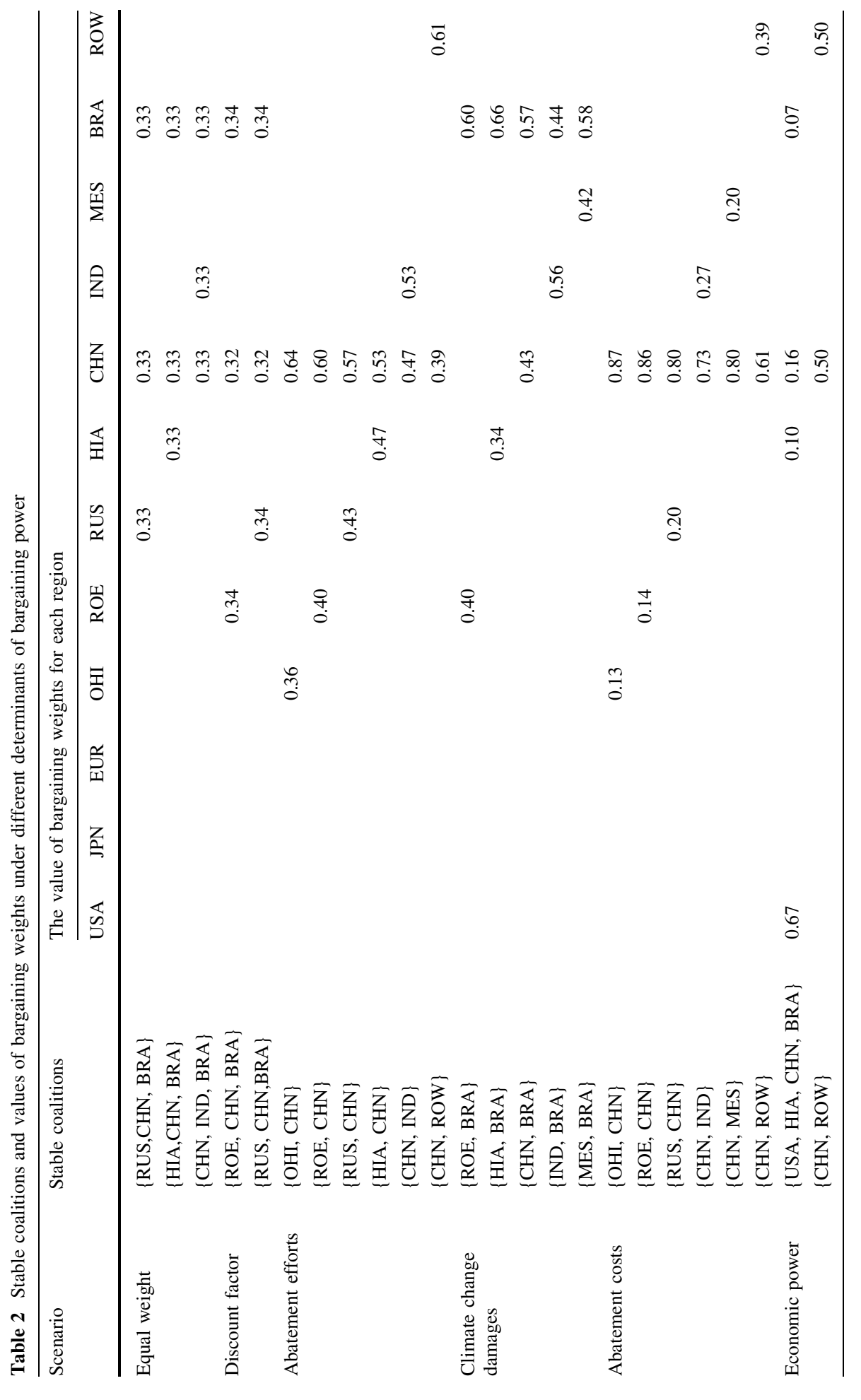


a singleton. Table 2 shows the results for stable coalitions and the value of bargaining weights for each signatory under different determinants of the bargaining power. The second column of Table 2 lists all stable coalitions for the five sets of asymmetric bargaining weights described in Sect. 3 and a reference scenario with equal weights. Under the scenario with equal bargaining weights, three coalitions (i.e. \{RUS, CHN, BRA\}, \{HIA, CHN, BRA $\}$ and $\{$ CHN, IND, BRA $\}$ ) are stable. In STACO, regions like RUS, $\mathrm{CHN}$ and IND are characterised by flat marginal abatement cost curves and by a moderate level of abatement benefits (see Table 6 and Fig. 2 in Appendix). In a coalition of regions with similar marginal abatement costs and benefits, participation incentives can be promoted and maintained with equal sharing of collective gains. Regions BRA and HIA face steep marginal abatement cost curves and low marginal benefit shares. Hence, when joining a coalition the required additional abatement remains limited. It is CHN that undertakes the largest abatement efforts but also not much more than under all singletons.

As shown in Table 2, generally, there are small stable coalitions under all sets of bargaining weights we examine. The reason is that for each set of asymmetric bargaining weights, only the regions with an advantage have sufficient incentives to join. For example, as our numerical results show, USA has strong incentives to join an ICA with members HIA, CHN and BRA when the bargaining weight is based on GDP, whereas among six stable coalitions only China, India and the rest of the world are motivated to join with large incentives when the bargaining weight is determined by abatement efforts. Our results also show that multiple equilibrium coalitions emerge under each set of bargaining weights. Generally, among all determinants, more coalitions can be stabilised when bargaining power is determined by signatories' abatement efforts, damages and abatement costs. It should be noticed that same stable coalitions can emerge under different sets of bargaining power; for example, coalitions $\{\mathrm{OHI}, \mathrm{CHN}\},\{\mathrm{ROE}, \mathrm{CHN}\}$ and $\{\mathrm{RUS}, \mathrm{CHN}\}$ can be stabilised with bargaining weights based on 'abatement efforts' and 'abatement costs'. Even though some regions' bargaining power can be interpreted as different values under different determinants, and the corresponding NBS in terms of the distribution of coalitional gains is also changed accordingly, the same equilibria with respect to the stable coalitions can still be reached. It is also interesting to see that, even though there are multiple equilibrium coalition structures for each distribution of bargaining weights, one coalition member is present in each equilibrium structure (CHN or BRA). This is due to their relatively larger bargaining weights under the respective set of weights (see Table 2).

When the bargaining weight is determined by regions' discount factors, regions with high discount rates, for example, CHN and IND, cannot strike an agreement with developed regions like USA, JPN and EUR which have low discount rates and induce large additional abatement efforts of CHN. Due to low discount rates (see Appendix Table 6), developed regions like USA, JPN and EUR are in a better bargaining position compared to regions that have high discount rates and $\mathrm{CHN}$ cannot recover the cost of abatement. However, as shown in Table 2, cooperation can be established between CHN and regions like ROE, BRA and RUS (e.g. \{ROE, CHN, BRA $\},\{$ RUS, CHN, BRA $\}$ ). To see why such coalitions can be stable, notice that ROE, RUS and BRA have low marginal benefits, requiring little extra abatement compared to disagreement. To shed more light on stability, consider Fig. 1 which depicts the payoff space for RUS and CHN in a coalition with BRA. This coalition is stable under equal and discounting bargaining weights. In Fig. $1, D=(836.58,283.52)$ is the disagreement point. BRA's payoff in that point is 244.52 and not reported in the figure. The downward sloping line depicts any payoff distribution between CHN and RUS when BRA receives its outside option payoff, a minimum requirement for internal stability. Hence, to the right of that line where RUS 
and $\mathrm{CHN}$ receive more and BRA receives less the coalition cannot be stable. The dashed vertical and horizontal lines depict the outside option payoffs of RUS and CHN, respectively. Only bargaining solutions that produce payoff vectors in the shaded triangle will be internally stable. We highlight three points in Fig. 1. Point $B=(884.80,289.66)$ is the best payoffs that BRA can obtain (288.22) in a stable coalition with RUS and CHN. Both RUS and CHN receive only their outside option payoff. Points $E=$ $(884.92,295.66)$ and $F=(885.31,294.38)$ are the bargaining solutions for equal bargaining weights and weights based on discounting. Both are stable as shown in Table 2 and very close to each other as shown in Fig. 1.

In scenarios where bargaining weights are based on abatement efforts and abatement costs, China is a member of all stable coalitions. This can be attributed to China's advantage in terms of low marginal abatement costs, which makes China contribute large shares to the total coalitional abatement. The large contribution to coalitional abatement puts China in a strong bargaining position, and it therefore receives a larger share of the gains. However, there are two exceptions of stable coalitions (i.e. $\{\mathrm{CHN}, \mathrm{IND}\}$ and $\{\mathrm{CHN}$, ROW \}), in which the bargaining weights of CHN are lower compared to IND and ROW (i.e. $\lambda_{\mathrm{CHN}}=0.47$ and 0.39 ), see Table 2 . This is due to the lower marginal abatement costs of IND and ROW as compared to CHN at the equilibrium abatement level.

Under bargaining weights determined by climate change damages, BRA always has more bargaining power because of its lowest benefit share. Hence, as shown in the scenario for damage weights in Table 2, BRA has generally a higher bargaining weight than its respective coalition partner (except when it forms a coalition with India) and thus appears in all stable coalitions in this scenario. Under bargaining weights determined by the economic power, USA holds an advantageous bargaining position in the negotiation. As shown in the last row of Table 2, USA has the largest bargaining weight in the coalition

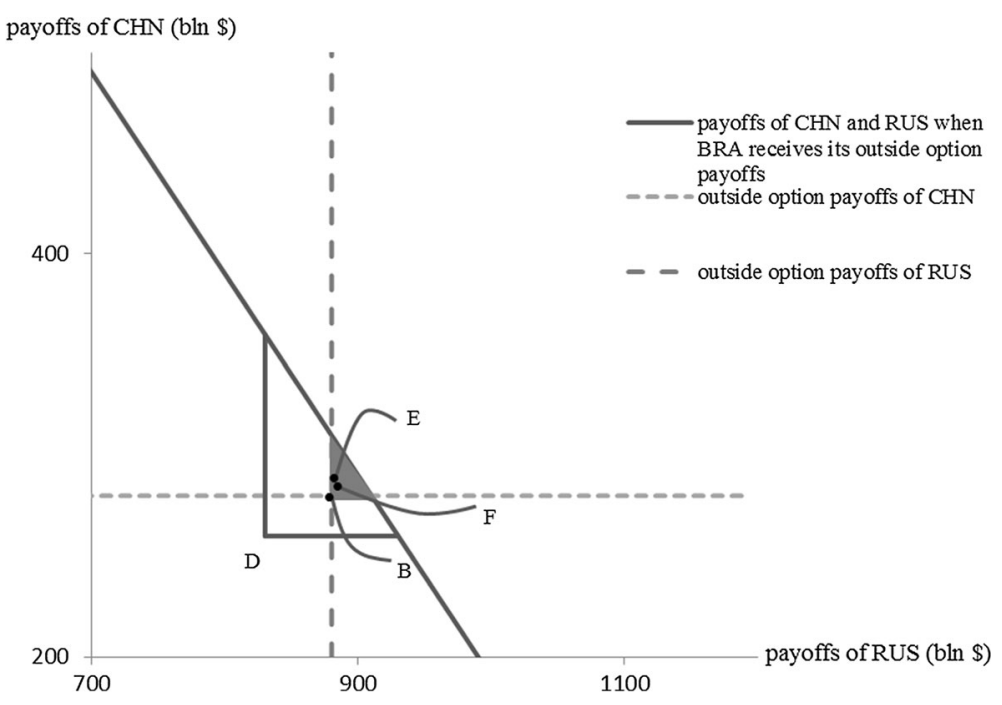

Fig. 1 Bargaining set for the coalition $\{$ RUS, CHN, BRA $\}$. The disagreement point is D. The bargaining set is the triangle to the north-east of D. Point B marks the outside option payoffs for RUS and CHN. The shaded triangle marks internally stable allocations 
\{USA, HIA, CHN, BRA\}. However, USA would prefer one of the other five bargaining weight scenarios since in these scenarios it would benefit from being a free rider. Our results also show that a stable cooperation between two regions with equal bargaining weights, like CHN and ROW, can also be reached.

In order to compare the performance of stable coalitions that we find under different sets of bargaining weights, we report more detailed results in Table 3. The table shows results for the best-performing stable coalitions in terms of the net present value of global payoffs for each set of bargaining weights. Table 3 shows that in general the set of bargaining weights that favours large emitters can lead to higher abatement and welfare levels.

Among the five sets of bargaining weights, the highest global abatement and welfare can be obtained under the coalition \{USA, HIA, CHN, BRA\} which is stable for bargaining weights determined by GDP. The reasons for this finding are, firstly, that the size of this coalition is the largest among all stable coalitions under different sets of bargaining weights; secondly, this is due to the participation of the world's two biggest GHG emitting countries USA and CHN. Their GHG emissions account for a large part of the world emissions; hence, the abatement level adopted by these two countries is also prominent for global abatement and welfare. This result also reflects the important impact of the participation by USA and CHN in the formation of ICAs. By contrast, the coalition $\{\mathrm{CHN}, \mathrm{BRA}\}$ that is stable when the bargaining weights are determined by damages offers the lowest global abatement and welfare in our set of scenarios. It is even Pareto dominated by \{USA, HIA, CHN, BRA\}. This result is straightforward to understand: compared to other regions BRA is a region with higher marginal abatement costs. Therefore, the equilibrium abatement level by BRA is lower, which results in the lowest global abatement and welfare obtained by coalition $\{\mathrm{CHN}, \mathrm{BRA}\}$. In the reference scenario with equal bargaining weights, the global abatement of the stable coalition $\{\mathrm{CHN}, \mathrm{IND}, \mathrm{BRA}\}$ is lower than what is achieved under other sets of asymmetric bargaining weights, except for the weights derived from damages. Nevertheless, the welfare obtained is higher, unless weights are determined by economic power. It can be concluded that signatories with low marginal abatement costs forming a coalition with a region with high marginal benefits lead to higher the abatement of the coalition. As shown in Table 3, the success of the coalition largely depends on the participation of both USA and CHN (cf. also Dellink 2011).

\subsection{Results for the Nash bargaining solution with outside options}

We introduced outside options to the NBS in Sect. 3 and discussed their role. We have argued that the NBS falls into the class of optimal sharing rules when outside options are considered. In this section, we examine the effects of outside options by comparing results from the STACO model for bargaining with outside options with the Nash bargaining outcomes of the previous subsection.

Under the NBS with outside options, signatories' redistributed payoffs consist of their outside option payoff plus a share of the remainder $\left(\sum_{i \in S} V_{i}(S)-\sum_{i \in S} V_{i}(S \backslash\{i\})\right)$. As noted earlier, the distribution of the remainder does not affect coalition stability. Thus, stability is independent of the bargaining weights when outside options matter. Our numerical results show a large improvement in the NBS if outside options matter. Both number and size of stable coalitions under the NBS with outside options can be improved as compared to the results for the NBS without outside options. There are more than 190 stable coalitions. Stable coalitions comprise up to six members (e.g. \{EUR, OHI, ROE, 


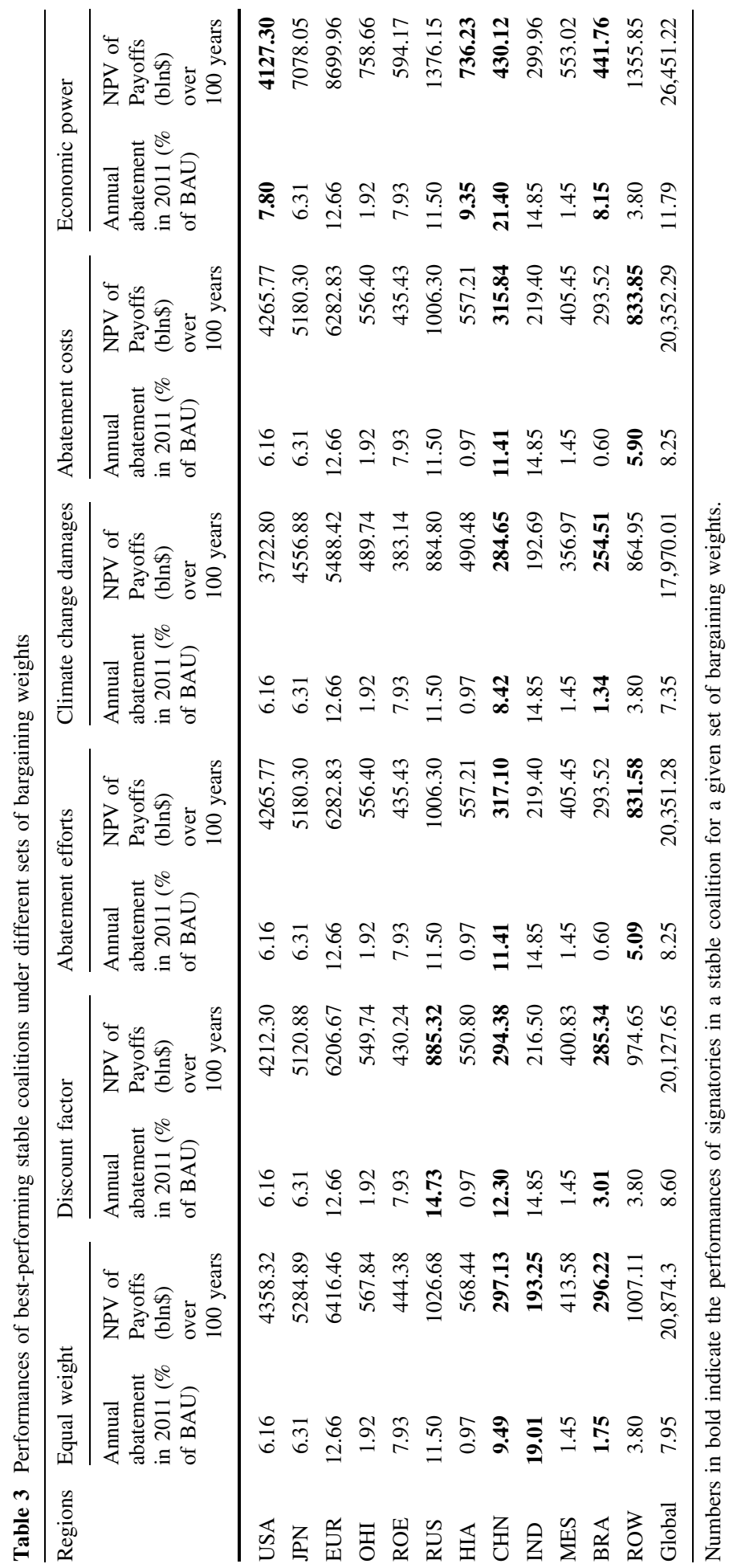


Table 4 Comparison of two best-performing stable coalitions that are formed under the NBS with and without outside options

\begin{tabular}{|c|c|c|c|c|}
\hline \multirow[t]{2}{*}{ Regions } & \multicolumn{2}{|c|}{$\begin{array}{l}\text { The best-performing stable coalition } \\
\text { under NBS with outside options: } \\
\{E U R, C H N, I N D, \text { ROW }\}\end{array}$} & \multicolumn{2}{|c|}{$\begin{array}{l}\text { The best-performing coalition without } \\
\text { outside options: \{USA, HIA, CHN, } \\
\text { BRA\} }\end{array}$} \\
\hline & $\begin{array}{l}\text { Annual abatement } \\
\text { in } 2011(\% \text { of } \\
\text { BAU) }\end{array}$ & $\begin{array}{l}\text { NPV of Payoffs } \\
\text { (bln\$) over } \\
100 \text { years }\end{array}$ & $\begin{array}{l}\text { Annual abatement } \\
\text { in } 2011 \text { ( } \% \text { of } \\
\text { BAU) }\end{array}$ & $\begin{array}{l}\text { NPV of Payoffs } \\
\text { (bln\$) over } \\
100 \text { years }\end{array}$ \\
\hline USA & 6.16 & 7542.84 & 7.80 & 4127.30 \\
\hline JPN & 6.30 & 8954.01 & 6.31 & 7078.05 \\
\hline EUR & 15.33 & 7548.66 & 12.66 & 8699.96 \\
\hline $\mathrm{OHI}$ & 1.92 & 958.24 & 1.92 & 758.66 \\
\hline ROE & 7.93 & 750.84 & 7.93 & 594.17 \\
\hline RUS & 11.50 & 1741.76 & 11.50 & 1376.15 \\
\hline HIA & 0.97 & 960.85 & 9.35 & 736.23 \\
\hline $\mathrm{CHN}$ & 25.25 & 449.87 & 21.40 & 430.12 \\
\hline IND & 39.22 & 329.31 & 14.85 & 299.96 \\
\hline MES & 1.45 & 698.92 & 1.45 & 553.02 \\
\hline BRA & 0.60 & 505.80 & 8.15 & 441.76 \\
\hline ROW & 21.23 & 1447.48 & 3.80 & 1355.85 \\
\hline Global & 15.95 & $31,888.57$ & 11.79 & $26,451.22$ \\
\hline Indicator of success $(\%)$ & 29.38 & 36.00 & 15.90 & 23.00 \\
\hline
\end{tabular}

Numbers in bold indicate the performances of signatories in a stable coalition. Indicator of success $(\%)$ : (NPV of global payoffs in a coalition-NPV of global payoffs in all singletons)/(NPV of global payoffs in grand coalition-NPV of global payoffs in all singletons) $\times 100$. A similar definition applies to abatement

CHN, MES, BRA $\},\{$ EUR, ROE, HIA, CHN, MES, BRA $\}$, \{EUR, ROE, HIA, IND, MES, BRA \}). This comparison confirms the advantage of the optimal sharing rule in reducing players' free-rider incentives (cf. Weikard and Dellink 2014).

Since outside options are independent of the bargaining weights, any set of bargaining weights will lead to the same set of stable coalitions. Hence, there is no need to report results for different sets of bargaining weights in Table 4. The best-performing stable coalition is \{EUR, CHN, IND, ROW\}. Table 4 reports the comparison of the two best-performing stable coalitions that are formed under the NBS with and without outside options, respectively. There are four members in each. In the case of bargaining with outside options, several large GHG emitters (EUR, CHN, IND) are engaged. The high abatement achieved not only generates large net gains for the coalition, but also brings significant positive externalities for outsiders. However, due to large free-riding incentives, the best-performing coalition is still of limited size. This enhancement of the abatement efficiency also confirms the numerical results of the optimal sharing scheme obtained by Carraro et al. (2006) and Weikard and Dellink (2014). As shown in the last row of Table 4, we use an 'indicator of success' to represent the coalition's efficiency in closing the welfare (or abatement) gap between all singletons and grand coalition. ${ }^{1}$ The

\footnotetext{
1 The performance of grand coalition is reported in Table 7 in Appendix.
} 
stable coalition generated by the NBS with outside options shows a significant improvement in decreasing the gap as compared to the coalition generated without outside options (i.e. 36 and $23 \%$ ).

\section{Discussions and conclusions}

In this paper, we examine the formation and performance of international climate agreements in a cartel game when the distribution of coalitional gains is based on the NBS. We consider different plausible sets of bargaining weights. Our analysis identifies and discusses some key factors driving heterogeneous negotiators' bargaining power in international climate negotiations for distributing cooperative gains. These potential determinants provide insights into countries' potential bargaining positions based on their different characteristics. Furthermore, we consider outside options in the Nash bargaining solution and discuss their role in improving the positive effect of the NBS on the formation and efficiency of ICAs. Our numerical analysis employs the STACO model to investigate the impact of the NBS with asymmetric bargaining power on the formation and efficiency of ICAs.

Firstly, by applying the NBS without outside options to distribute coalitional gains, players' incentives to participate and abate can be increased, although to a limited degree. The effects vary under different sets of bargaining weights. As numerical results in SubSect. 4.2 show, only small coalitions can be stabilised when bargaining weights are determined according to abatement efforts, abatement costs and climate change damages. Our result is in line with the stability results of Weikard et al. (2006), where the coalitional surplus is shared among signatories based on different exogenous claims. In contrast, the size and performance of stable coalitions can be improved when bargaining weights are determined according to the discount factor or economic power.

Secondly, the NBS with outside options is more conducive to ICAs as compared to the bargaining solution without considering outside options. As discussed in subsect. 3.6, the bargaining outcome falls into the class of optimal sharing rules when outside options are considered. The numerical results in terms of stability and performances of international climate coalitions under the bargaining solution with outside options underline the advantage of such transfers. Our analysis provides a rationale for the use of optimal sharing rules: they result from a NBS with outside options (cf. Muthoo 1999).

Thirdly, multiple equilibrium climate coalitions can emerge from the NBS. In particular, under bargaining with outside options we find a large number of equilibrium coalitions. This finding is comparable to Carraro et al. (2006) and Nagashima et al. (2011), where multiple equilibrium coalitions can form when optimal sharing schemes are implemented.

Moreover, it turns out that by applying the NBS to the distribution of coalitional gains, the success of international climate agreements depends on the set of bargaining weights that matters in climate negotiation. Our analysis suggests that some sets of bargaining weights generate more successful coalitions in terms of welfare and abatement than others. For example, among five sets of asymmetric bargaining weights, the one determined by negotiators' economic power can facilitate a climate coalition that comprises two of the largest emitters (CHN and USA) jointly with two other regions. 
Our study has some immediate policy implications. Firstly, an ICA should be designed to attract large GHG emitters. Generally, regions with higher GDP produce more emissions, like USA, China or India. Thus, when regions with more economic power (higher GDP) can benefit more from an agreement, they will have stronger incentives to join and, hence, more successful ICAs can be formed. It might be controversial that economic power shapes negotiations and determines outcomes. However, it should be noticed that economically powerful regions with a high GDP may include regions with a relatively low GDP per capita, such as China or India when compared to USA. Secondly, in the negotiation process multiple determinants of bargaining power will play a role. This is because one country's incentives to cooperate on GHG mitigation are impacted in a complex way by factors that are related to abatement options, climate change vulnerability and economic power. The bargaining power of each negotiator is likely to be driven by multiple determinants.

One direction to extend our analysis is to study negotiators' strategic behaviour when bargaining power becomes an endogenous variable. ${ }^{2}$ This requires an extended dynamic game setting where pre-negotiations determine the negotiation protocol (Wangler et al. 2013), and therefore, bargaining powers are relevant at the later stages of the game.

Acknowledgements The first author acknowledges support by the Erasmus Mundus EURASIA 2 (www. eurasia2.cz) programme. We thank two anonymous reviewers for their constructive comments.

Open Access This article is distributed under the terms of the Creative Commons Attribution 4.0 International License (http://creativecommons.org/licenses/by/4.0/), which permits unrestricted use, distribution, and reproduction in any medium, provided you give appropriate credit to the original author(s) and the source, provide a link to the Creative Commons license, and indicate if changes were made.

\section{Appendix}

See Tables 5, 6 and 7 and Fig. 2.

Table 5 Regional aggregation in the STACO 3

\begin{tabular}{ll}
\hline STACO 3 & Names \\
\hline USA & United States \\
JPN & Japan \\
EUR & EU27 \& EFTA \\
OHI & Other High Income \\
ROE & Rest of Europe \\
RUS & Russia \\
HIA & High Income Asia \\
CHN & China \\
IND & India \\
MES & Middle East \\
BRA & Brazil \\
ROW & Rest of the world \\
\hline
\end{tabular}

\footnotetext{
${ }^{2}$ We thank an anonymous reviewer for this comment.
} 
Table 6 Discount rate, GDP and abatement benefit share of twelve regions in STACO 3

\begin{tabular}{llrl}
\hline & Discount rates & GDP in the year 2011(Billion \$) & Regional shares of benefits $\left(\theta_{i}\right)$ \\
\hline USA & 0.0517 & $12,807.0$ & 0.2263 \\
JPN & 0.0359 & 4831.4 & 0.1725 \\
EUR & 0.0388 & $13,708.0$ & 0.2491 \\
OHI & 0.0636 & 1672.5 & 0.0345 \\
ROE & 0.0612 & 615.2 & 0.0271 \\
RUS & 0.0397 & 729.4 & 0.0403 \\
HIA & 0.0474 & 1973.4 & 0.0300 \\
CHN & 0.1117 & 3160.0 & 0.0620 \\
IND & 0.1444 & 803.2 & 0.0500 \\
MES & 0.0470 & 827.7 & 0.0249 \\
BRA & 0.0442 & 1266.0 & 0.0153 \\
ROW & 0.0530 & 3158.6 & 0.0680 \\
Global & - & $45,552.4$ & $\left(\sum \theta_{i}=1\right)$ \\
\hline
\end{tabular}

Table 7 All singletons and grand coalition

\begin{tabular}{|c|c|c|c|c|}
\hline \multirow[b]{2}{*}{ Regions } & \multicolumn{2}{|l|}{ All singletons } & \multicolumn{2}{|l|}{ Grand coalition } \\
\hline & $\begin{array}{l}\text { Annual } \\
\text { abatement } \\
\text { in } 2011 \\
\text { (\% of BAU } \\
\text { emissions) }\end{array}$ & $\begin{array}{l}\text { Net present value } \\
\text { (NPV) of payoffs } \\
\text { (Billion \$) over } \\
100 \text { years }\end{array}$ & $\begin{array}{l}\text { Annual abatement } \\
\text { in } 2011 \text { ( } \% \text { of } \\
\text { BAU emissions) }\end{array}$ & $\begin{array}{l}\text { Net present value } \\
\text { (NPV) of payoffs } \\
\text { (Billion } \$ \text { ) over } \\
100 \text { years }\end{array}$ \\
\hline USA & 6.16 & 3507.55 & 25.87 & $12,795.98$ \\
\hline JPN & 6.30 & 4309.52 & 23.88 & $18,569.78$ \\
\hline EUR & 12.66 & 5173.23 & 32.13 & $21,508.83$ \\
\hline $\mathrm{OHI}$ & 1.92 & 463.33 & 37.08 & 1429.88 \\
\hline ROE & 7.93 & 362.42 & 50.64 & 911.18 \\
\hline RUS & 11.50 & 836.58 & 50.13 & 2292.19 \\
\hline HIA & 0.97 & 464.00 & 29.85 & 609.19 \\
\hline $\mathrm{CHN}$ & 6.77 & 283.53 & 39.64 & -1353.45 \\
\hline IND & 14.85 & 182.14 & 58.38 & 21.21 \\
\hline MES & 1.45 & 337.73 & 73.04 & 367.20 \\
\hline BRA & 0.60 & 244.52 & 20.23 & 393.91 \\
\hline ROW & 3.80 & 816.73 & 40.94 & 1027.70 \\
\hline Global & 6.88 & $16,981.28$ & 37.73 & $58,573.6$ \\
\hline
\end{tabular}




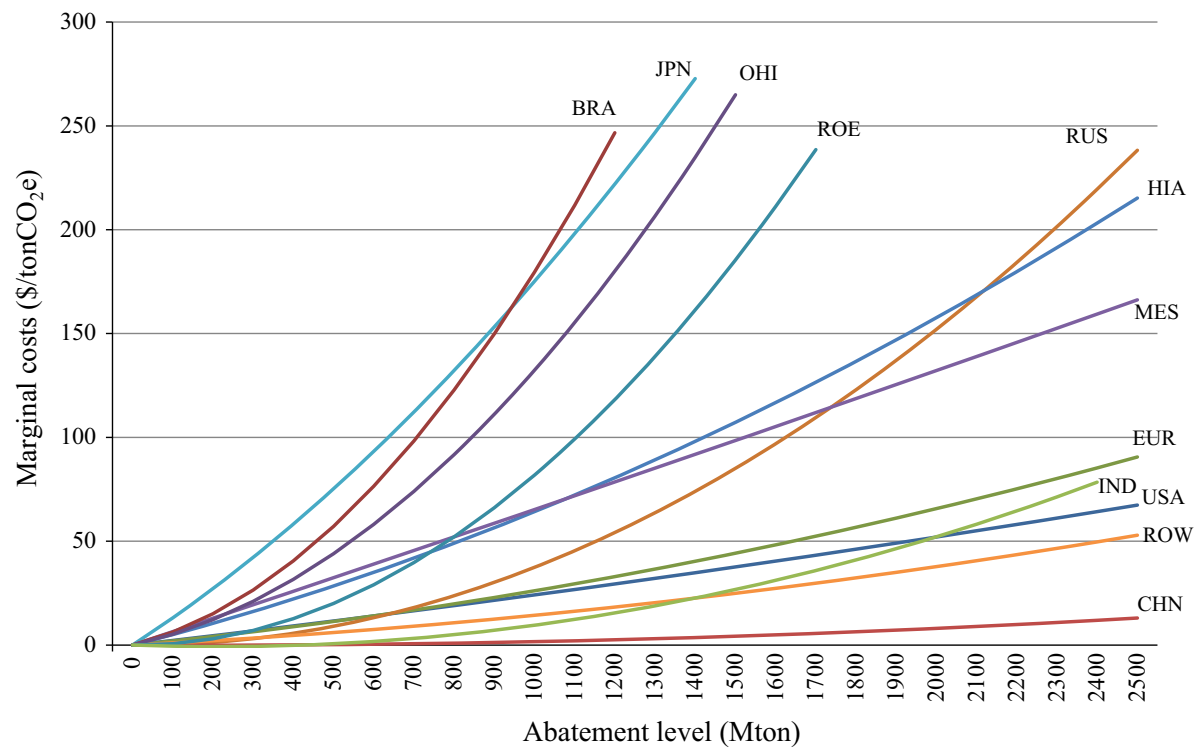

Fig. 2 Marginal abatement cost curves in 2011 in the STACO 3 model

\section{References}

Altamirano-Cabrera, J.-C., \& Finus, M. (2006). Permit trading and stability of international climate agreements. Journal of Applied Economics, 9, 19-48.

Asheim, G. B., Bretteville Froyn, C., Hovi, J., \& Menz, F. C. (2006). Regional versus global cooperation for climate control. Journal of Environmental Economics and Management, 51, 93-109.

Barrett, S. (1995). Heterogeneous international environmental agreements. Milano: Fondazione ENI Enrico Mattei.

Barrett, S., \& Stavins, R. (2003). Increasing participation and compliance in international climate change agreements. International Environmental Agreements Politics Law and Economics, 3(4), 349-376.

Bernheim, B. D., Peleg, B., \& Whinston, M. D. (1987). Coalition-proof Nash equilibria I. Concepts. Journal of Economic Theory, 42, 1-12.

Binmore, K., Osborne, M. J., \& Rubinstein, A. (1992). Noncooperative models of bargaining. In R. J. Aumann \& S. Hart (Eds.), Handbook of game theory, (Vol. 1, pp. 179-225). North Holland: Amsterdam.

Binmore, K., Rubinstein, A., \& Wolinsky, A. (1986). The Nash bargaining solution in economic modelling. The Rand Journal of Economics, 17, 176-188.

Botteon, M., \& Carraro, C. (1997). Burden-sharing and coalition stability in environmental negotiations with asymmetric countries. In C. Carraro (Ed.), International environmental negotiations: Strategic policy issues (pp. 26-55). Cheltenham: Edward Elgar.

Carraro, C., Eyckmans, J., \& Finus, M. (2006). Optimal transfers and participation decisions in international environmental agreements. The Review of International Organizations, 1(4), 379-396.

Carraro, C., \& Siniscalco, D. (1993). Strategies for the international protection of the environment. Journal of Public Economics, 52(3), 309-328.

Carraro, C., \& Siniscalco, D. (1995). R\&D cooperation and the stability of international environmental agreements (No. 1154). CEPR Discussion Papers.

Chwe, M. S. Y. (1994). Farsighted coalitional stability. Journal of Economic Theory, 63(2), 299-325.

Costantini, V., Sforna, G., \& Zoli, M. (2015). Interpreting bargaining strategies of developing countries in climate negotiations-A quantitative approach. SEEDS Working Paper.

Courtois, P., \& Tazdaït, T. (2014). Bargaining over a climate deal: Deadline and delay. Annals of Operations Research, 220, 205-221.

d'Aspremont, C., Jaquemin, A., Gabszewicz, J. J., \& Weymark, J. A. (1983). On the stability of collusive price leadership. Canadian Journal of Economics, 16(1), 17-25. 
De Zeeuw, A. (2008). Dynamic effects on the stability of international environmental agreements. Journal of Environmental Economics and Management, 55(2), 163-174.

Dellink, R. (2011). Drivers of stability of climate coalitions in the STACO model. Climate Change Economics, 2(2), 105-128.

Dellink, R.B., de Bruin, K., Nagashima, M., van Ierland, E.C., Urbina-Alonso, Y., Weikard, H.-P., \& Yu, S. (2015). STACO Technical document 3: Model description and calibration of STACO 3. Wageningen School of Social Sciences, Working Paper No. 12, Wageningen University.

Finus, M. (2003). Stability and design of international environmental agreements: the case of transboundary pollution. In H. Folmer \& T. Tietenberg (Eds.), The International yearbook of environmental and resource economics 2003/2004 (pp. 82-152). Cheltenham: Edward Elgar.

Finus, M., Saiz, M. E., \& Hendrix, E. M. (2009). An empirical test of new developments in coalition theory for the design of international environmental agreements. Environment and Development Economics, 14(1), 117-137.

Muthoo, A. (1999). Bargaining theory with applications. Cambridge: Cambridge University Press.

Nagashima, M., Dellink, R., Van Ierland, E., \& Weikard, H. P. (2009). Stability of international climate coalitions-a comparison of transfer schemes. Ecological Economics, 68(5), 1476-1487.

Nagashima, M., Weikard, H.-P., de Bruin, K., \& Dellink, R. (2011). International climate agreements under induced technological change. Metroeconomica, 62(4), 612-634.

Nash, J. F. (1950). The bargaining problem. Econometrica, 18(2), 155-162.

Powell, R. (2002). Bargaining theory and international conflict. Annual Review of Political Science, 5, 1-30.

Rose, A., \& Stevens, B. (1998). A dynamic analysis of fairness in global warming policies: Kyoto, Buenos Aires, and beyond. Journal of Applied Economics, 1, 329-362.

Rose, A., Stevens, B., Edmonds, J., \& Wise, M. (1998). International equity and differentiation in global warming policy. Environmental \& Resource Economics, 12(1), 25-51.

Rubinstein, A. (1982). Perfect equilibrium in a bargaining model. Econometrica, 50(1), 97-109.

Sáiz, M. E., Hendrix, E. M., \& Olieman, N. J. (2006). On the computation of stability in multiple coalition formation games. Computational Economics, 28(3), 251-275.

Wagner, R. H. (1988). Economic interdependence, bargaining power, and political influence. International Organization, 42(03), 461-483.

Wangler, L. U., Altamirano-Cabrera, J.-C., \& Weikard, H. P. (2013). The political economy of international environmental agreements: A survey. International Environmental Agreements Politics Law and Economics, 13(3), 387-403.

Weikard, H. P. (2009). Cartel stability under an optimal sharing rule. The Manchester School, 77(5), $575-593$.

Weikard, H. P., \& Dellink, R. (2014). Sticks and carrots for the design of international climate agreements with renegotiations. Annals of Operations Research, 220(1), 49-68.

Weikard, H. P., Finus, M., \& Altamirano-Cabrera, J. C. (2006). The impact of surplus sharing on the stability of international climate agreements. Oxford Economic Papers, 58(2), 209-232. 